\title{
Analysis and visualization of blocks stability in rock slope based on UAV technology: a case study of Shenxianju
}

\author{
${ }^{1}$ College of Architecture and Civil Engineering, Xi'an University of Science and Technology, Xi'an, 710054, China; *Corresponding author, \\ E-mail: gbl8001@126.com \\ ${ }^{2}$ China Jikan Research Institute of Engineering Investigations and Design, Co. LTD, Xi'an 710043, China \\ ${ }^{3}$ Suzhou FaceAll Technology Co. Ltd., Suzhou, 215124, China \\ ${ }^{4}$ Institute of Geology and Geophysics, Chinese Academy of Sciences, Beijing, 100029, China
}

(Received: May 11, 2021; Revised accepted: November 29, 2021)

https://doi.org/10.18814/epiiugs/2021/021035

In order to solve the problems of collapse and sliding blocks of rock slopes engineering, it is crucial to analyze the stability of blocks. In this paper, we take the rocky and high steep slope of Shenxianju Scenic Area in Xianju County, Zhejiang Province, as a research instance to investigate the improvement of block stability analysis efficiency and visualization. Based on the coordinate projection method, the determination method of block geometric conditions and the calculation method of stability coefficient is proposed. Then, through combining the coordinate projection method and UAV measurement technology, the CPS program suitable for analyzing the stability of planar polyhedron blocks and curved surface blocks in rock slope engineering has been developed based on MATLAB to realize the spatial representation and visualization of unstable blocks. The program can determine the geometric conditions of blocks conveniently, realize the stability analysis and visualization of blocks. Also, an engineering application shows that the study can effectively and accurately deal with the common engineering geological disasters such as rockfall and collapse. The developed program can realize the visualization of rock slope model, its analysis results are basically consistent with the Q-slope method. That is to say, this analysis method for block stability is reliable, which can greatly improve the efficiency of block stability analysis of rock slope with practical engineering significance.

\section{Introduction}

According to the view of engineering geomechanics, rock mass is composed of structural planes and structural bodies surrounding it. Nevertheless, the structural body is a unit rock block cut by the structural plane. Therefore, the structural body stability determines the rock mass stability (Yang, 1978; Gu, 1983; Wang et al., 1984; Cai et al., 2002). Many engineering practices have revealed that the rock mass failure is mostly the instability failure of blocks in rock slope.
Also, it is shown that the classification of surrounding rock and the design of surrounding rock support in rock slope engineering is closely related to the stability of blocks. Overall, in the design and construction of rock slope, the block stability analysis is an extremely important section for studying the overall stability of the rocks surrounding rock slope.

There are many commonly used methods of block geometric conditions and block stability analyses, e.g., the numerical method, the stereographic projection diagram method, the coordinate projection method (Yang et al., 2009). Goodman and Shi (1985) put forward a block theory systematically, which could be used to solve the block recognition and stability analysis problem formed by the combination of arbitrary structural planes and free faces in space. Also, based on topological principles, Shi (1977) used stereographic projection and vector operation approaches to study the combined relationship between structural planes and free faces so as to analyze the blocks that might be generated after the excavation of slope and tunnel. Sun and $\mathrm{Gu}$ (1984) used stereographic projection to perform block identification and block stability analyses in rock engineering. However, the stereographic projection method is very cumbersome and time-consuming in the field of rock slope stability analysis.

Azarafza et al. (2020) introduced a simplified semi-distinct element algorithm for discontinuous rock slopes under toppling instability assessment based on block theory. Zhang et al. (2017) compared the application of block theory and three-dimensional (3D) block-cutting analysis to understand the shortcomings of classic block theory and properly utilize the benefits gained from 3D block-cutting analysis, then, they could deal with more complicated issues. Ma et al. (2020) analysed the deformation and instability of discontinuity-controlled rock slope by three-dimensional discontinuous deformation analysis (3D-DDA). It was found that the simulation of the critical sliding state of blocks by 3D-DDA was effective after improvement of the critical sliding model of joint contact between blocks, and the computational results showed good agreement with monitoring results. Jiang and Zhou (2017) presented a new method that permits to consider the contribution of the normal forces and shear resistances acting on each discontinuity plane to the block stability.

Zhang et al. (2020) introduced the basic analysis procedure of the 
General Block (GB) method and discussed the stability of rock blocks in an underground hydropower station at the Three Gorges Project. Kesong et al. (2020) proposed a robust contact detection algorithm in the 3D-DDA for convex polyhedral blocks based on the Contact Theory. Also, Liu et al. (2019) presented an integrated system coupling 3D-DDA and UAV-LS photogrammetry as a tool to evaluate the stability of a blocky rock mass slope.

Lin et al. (1987) studied the recognition of complex geometric blocks in a three-dimensional space based on topology principles, and Yang et al. (2015) realized fast closed block search based on a 3D geological topology model. In addition, Azarafza et al. (2020) presented a fuzzy logical decision-making algorithm based on block theory to determine discontinuous rock slope reliability under various wedge and planar slip scenarios effectively. Ikegawa and Hudson (1992) proposed more concepts, such as directed body, sagittal plane, and edge vector, and they carried out the block search on this basis. Yu et al. (2007) conducted an arbitrary block search and a stability analysis in a three-dimensional space by setting the excavation face of a slope or cavern, and they compiled the utility program General Block. Yang et al. (1985) combined stereographic projection and orthographic projection to propose a coordinate projection method, and they applied it to the analysis of block stability in rock engineering.

There are superiorities and deficiencies with the various research methods of block stability analysis above. Overall, there are two aspects that need to be strengthened: 1) The comprehensive integration of structural planes and free faces obtained from a field survey are very important, but the existing research methods mention it rarely. 2) The research object of some methods is single block, such as the stereographic projection method, therefore the research on multiple blocks needs to be deepened.

Considering that the coordinate projection method could express the geometric conditions of a block conveniently, meaning that it could solve the problem of describing the geometric conditions of the complex shape of a block or multiple blocks well, so this study was conducted based on the coordinate projection method to investigate the stability of a rock slope block in Shenxianju, Xianju County, Zhejiang Province.

However, the coordinate projection diagram of blocks, especially multiple blocks, is relatively complex, and the drawing efficiency is not high, Gao (2005) computerized it and developed a block stability analysis program in 2003 . Nevertheless, this program can only be used to calculate blocks with the shape of a tetrahedral plane, it can not calculate blocks with the shape of polyhedral planes and curved surface blocks in rock slope. Therefore, it is necessary to conduct further studies on the stability of plane polyhedrons and curved surface blocks of rock slope, and develop the CPS program to realize their analysis and visualization.

\section{Analysis Method}

\section{Coordinate Projection Principle}

The coordinate projection method (Yang, 1985; Gao, 2005; Yang et al., 2006; Yuan et al., 2007; Yuan et al., 2009) is a graphical method in the rectangular coordinate system, it realizes the combination of orthographic projection and stereographic projection, and the geometric conditions and stability of blocks cut by structural planes and free faces in regards to rock mass engineering are analyzed through this combination. It is theoretically based on rock engineering geomechanics, descriptive geometry and stereographic projection.

When analyzing the stability of a block based on the coordinate projection principle, first, the block cut by structural planes and free faces is analyzed quantitatively, which means that the shape and position are determined including the volume and surface area (boundaries) of the block. Then, it is necessary to solve the stability coefficient of blocks through the stability analysis method to identify any potentially unstable blocks in order to evaluate the overall stability of rock slope.

\section{Block Geometry Recognition}

To analyze the stability of a block in rock slope, it is necessary to find the exposed blocks on the free face of rock slope, where the location, shape, and stability of these blocks are the main focus of research. Also, multiple groups of structural planes and free faces must form a closed space to be considered as a closed block, and the premise for structural planes to cut each other to form a closed block is that the exposed traces of structural planes on the free face must be a closed-loop.

\section{Structural plane and free face determination}

In space, the structural plane of a rock mass is approximately flat, while most of the free faces are curved. We proposed a linear regression fitting method for determining the structural plane equation (Gao et al., 2021). For example, on a structural plane, by selecting as many points as possible that are not on the same straight line, the space coordinates of these points are used to fit the linear regression equations in order to obtain the structural plane equations. Also, aiming at determining the free face, this study adopted the NURBS modeling method (Fan, 2004; Song et al., 2015), that is, the Non-Uniform Rational B-Splines method, to use the point cloud data on the free face of a rock mass in order to construct the free face equations.

According to the partial regression coefficients $\lambda_{0}, \lambda_{1}$ and $\lambda_{2}$ of structural plane equations fitted by linear regression, the normal vector of structural plane can be obtained as $\left(-\lambda_{1},-\lambda_{2}, 1\right)$, and then the dip direction $\alpha$ and $\operatorname{dip} \beta$ of the structural plane of rock mass can be calculated according to the following formulas:

$$
\begin{aligned}
& \beta=\arccos \frac{1}{\sqrt{\lambda_{1}^{2}+\lambda_{2}^{2}+1}} \\
& \text { If }-\lambda_{1} \geq 0,-\lambda_{2} \geq 0, \alpha=\arcsin \left(-\lambda_{1} / \sin \beta\right) \\
& \text { If }-\lambda_{1}<0,-\lambda_{2}>0, \alpha=360^{\circ}-\arcsin \left(\lambda_{1} / \sin \beta\right) \\
& \text { If }-\lambda_{1}<0,-\lambda_{2}<0, \alpha=180^{\circ}-\arcsin \left(-\lambda_{1} / \sin \beta\right) \\
& \text { If }-\lambda_{1}>0,-\lambda_{2}<0, \alpha=180^{\circ}+\arcsin \left(\lambda_{1} / \sin \beta\right)
\end{aligned}
$$

It is necessary to determine the extension range of structural plane after confirming the occurrence information about it. In order to simplify the calculation, assuming that the structural plane is a disk, this disk takes the distance between the farthest two points on the trace line as the diameter, and determines the spatial extension direction by the occurrence information. 


\section{Calculation of the intersection line of the structural plane and block vertex}

Assuming that the center coordinates of two structural planes are $O_{1}\left(x_{1}, y_{1}, z_{1}\right), O_{2}\left(x_{2}, y_{2}, z_{2}\right)$, their radiuses are $R_{1}, R_{2}$, and normal vectors are $\left(l_{1}, m_{1}, n_{1}\right)$ and $\left(l_{2}, m_{2}, n_{2}\right)$, if there is an intersection between the two structural planes, the direction vector of the intersection is $\mathbf{s}=\left(m_{1} n_{2}-n_{1} m_{2}, n_{1} l_{2}-l_{1} n_{2}, l_{1} m_{2}-m_{1} l_{2}\right)$. The coordinates of a point on the intersection are denoted as $M\left(x_{m}, y_{m}, z_{m}\right)$. Then, if the following formula has a solution, the two structural planes will have an intersection. However, if there is no solution, the two structural planes will not intersect each other.

$$
\left\{\begin{array}{c}
l_{1}\left(x_{m}-x_{1}\right)+m_{1}\left(y_{m}-y_{1}\right)+n_{1}\left(z_{m}-z_{1}\right)=0 \\
l_{2}\left(x_{m}-x_{2}\right)+m_{2}\left(y_{m}-y_{2}\right)+n_{2}\left(z_{m}-z_{2}\right)=0 \\
\frac{\left|\mathrm{O}_{1} \mathrm{M} \times \mathrm{s}\right|}{[\mathrm{s}]} \leq R_{1} \\
\frac{\left|\mathrm{O}_{2} \mathrm{M} \times \mathrm{s}\right|}{[\mathrm{s}]} \leq R_{2}
\end{array}\right.
$$

Assuming that the plane equations of three structural planes are $A_{i} x+B_{i} y+C_{i} z+D_{i}=0, A_{j} x+B_{j} y+C_{j} z+D_{j}=0, A_{k} x+B_{k} y+C_{k} z$ $+D_{k}=0$ and that their radiuses are $R_{1}, R_{2}, R_{3}$, if the three structural planes have intersections, the calculation formula of the coordinates of these intersections are as follows:

$$
\left\{\begin{array}{c}
A_{i} x+B_{i} y+C_{i} z+D_{i}=0 \\
A_{j} x+B_{j} y+C_{j} z+D_{j}=0 \\
A_{k} x+B_{k} y+C_{k} z+D_{k}=0 \\
\left(x-x_{1}\right)^{2}+\left(y-y_{1}\right)^{2}+\left(z-z_{1}\right)^{2} \leq R_{1}^{2} \\
\left(x-x_{2}\right)^{2}+\left(y-y_{2}\right)^{2}+\left(z-z_{2}\right)^{2} \leq R_{2}^{2} \\
\left(x-x_{3}\right)^{2}+\left(y-y_{3}\right)^{2}+\left(z-z_{3}\right)^{2} \leq R_{3}^{2}
\end{array}\right.
$$

After solving the coordinates of the intersection points of structural planes, it is still necessary to judge whether the intersection points are inside the rock slope or not. On a rocky slope with the same $\mathrm{x}$-axis and $y$-axis coordinates, when the z-axis coordinate of the intersection point is less than the $\mathrm{z}$-axis coordinate of the same $\mathrm{x}$-axis and $\mathrm{y}$-axis coordinate points on the rocky slope, it means that the intersection point is inside the rocky slope.

\section{A closed-loop formed on the free face}

After cutting a rock mass by a structural plane, many blocks are formed. Among these blocks, only the stability of a few finite blocks that can be moved is analyzed. The primary condition for a block to be movable is that its boundary is composed of edges, where the boundaries of a block are called edges. Also, to form a closed block, all the structural plane traces on the block's free face should form a closed-loop.

The following process can determine whether a block on a free face can form a closed-loop : (1) Calculate the intersections between a structural plane and other structural planes. (2) If the number of intersections is greater than 1 (Otherwise, it can be directly determined as an invalid structural plane.), project this structural plane onto the XOY plane. (3) Calculate the intersection between the line segments on the XOY plane. (4) Search and delete lines segments with nodes less than 2. (5) If those line segments cannot be deleted and 3 or more nodes remain, these structural planes can form a loop.

After the closure of the structural plane is judged on the free face, the exposed surface of the block unit is formed on the free face.

The Euler theorem of polyhedrons can be used to determine whether a block is formed after obtaining the number of faces, edges, and vertices of it. According to the theorem, for a simple polyhedron, there is a well-known Euler formula for the number of vertices V, number of edges $\mathrm{E}$, and number of faces $\mathrm{F}$ : $\mathrm{V}-\mathrm{E}+\mathrm{F}=2$. Through continuous surface deformation, a simple polyhedron can become a curved polyhedron.

\section{Geometric analysis of blocks}

After finding a closed block on a free face, it is necessary to perform a geometric analysis on the block to determine whether it has the possibility of instability and find its volume and structural plane area.

(1) Determination of blocks of oblique sliding surface

First, the sliding surface of the block is needed for the geometric analysis. For rock slope blocks, the most common ones are singleslip-surface-type blocks and double-slip-surface -type blocks. It is generally believed that a block with an anti-dip sliding surface is stable and not conducive to sliding, so this article only discusses the blocks with down-dip sliding surfaces.

Denote the sliding direction of a closed block with a down-dip surface on the free face as the vector $\mathbf{S}$. Then, $\mathbf{S}$ must meet the following conditions:

$$
\boldsymbol{n}_{\boldsymbol{i}} \cdot \mathbf{S} \geq 0,(i=1, \ldots, N)
$$

where $\boldsymbol{n}_{\boldsymbol{i}}$ is the unit normal vector of each boundary surface pointing to the inside.

The physical meaning of the above formula is that all interfaces of the block cannot hinder it from sliding. The inner product of the normal and sliding vectors on the two structural planes is not less than zero, which does not restrict the block from sliding, so this block may be unstable. If the angle between the normal vector and the sliding vector of the third structural plane is an obtuse angle, which prevents the block from moving in this direction, and the block can be considered stable.

(2) Determination of the area and volume of structural interface of a block

The structural plane area can be obtained by using the area projection method based on the orthographic projection principle and the inclination of the structural plane. For example, if the interface area of a block structure surface is $S$ the inclination angle is $\beta$, the structure surface area can be represented by using its projected area $S_{\mathrm{H}}$ on the (XOY) horizontal plane.

$$
S=S_{H} / \cos \beta
$$

In the same way, if the interface of the block structure plane is not perpendicular to the $\mathrm{XOZ}$ and $\mathrm{YOZ}$ planes, the structure plane area can be obtained from the projection on XOZ plane and $\mathrm{YOZ}$ plane.

The area $S_{\mathrm{H}}$ of the structural plane projected on the horizontal plane can be calculated by the following method:

The vector product of the two vectors is twice the area of the trian- 
gle enclosed by the two vectors. The boundary nodes are sorted clockwise as $A_{1}, A_{2}, A_{3}, A_{4}$, and $A_{5}$. If the origin is $O(0,0,0)$, the area of the pentagon can be obtained as:

$S_{H}=\frac{1}{2} \times\left|\overrightarrow{O A_{1}} \times \overrightarrow{O A_{2}}+\overrightarrow{O A_{2}} \times \overrightarrow{O A_{3}}+\overrightarrow{O A_{3}} \times \overrightarrow{O A_{4}}-\overrightarrow{O_{1}} \times \overrightarrow{O A_{5}}-\overrightarrow{O A_{5}} \times \overrightarrow{O A_{4}}\right|$

Since the free face of the curved block may be an irregular curved surface, some of the line segments in the polygon may be curved. Therefore, the method of dividing the surface interface into small areas is used, and the interface area $S$ is solved.

For the volume of the planar and curved blocks, it can be solved using microtomy, which has the superiority of easy computer programming. Generally speaking, microtomy is an approximation method that refers to using a group of imaginary auxiliary planes paralleled to a certain projection plane divides the block into many slices so as to obtain the volume of each slice, and then the volume of the block is replaced by the sum of the volumes of each slice.

Cut the block with $n$ parallel sections $R_{1}, R_{2}, \ldots R_{n}$ get $n+1$ slices (denoted as $1,2, \ldots, n+1$, respectively). Supposing that the distances between every two adjacent slices are $l_{2}, \ldots l_{n}$ the area of each slice is recorded as $S_{1}, S_{2}, \ldots, S_{n}$, slice 1 and slice $n+1$ are regarded as pyramids, and 2, 3,.., $n$ slices are regarded as frustums. The volume calculation formula of the block is:

$$
V=\frac{1}{3}\left(S_{1} \cdot l_{1}+S_{n} \cdot l_{n+1}\right)+\frac{1}{3} \sum_{i=2}^{n} l_{i}\left(S_{i-1}+S_{i}+\sqrt{S_{i-1} \cdot S_{i}}\right)
$$

If the slices are thinner, the top and bottom surfaces of the frustums are represented by their average values, approximately. The above formula can be simplified as:

$$
V=\frac{1}{3}\left(S_{1} \cdot l_{1}+S_{n} \cdot l_{n+1}\right)+\frac{1}{2} \sum_{i=2}^{n} l_{i}\left(S_{i-1}+S_{i}\right)
$$

\section{Calculation Method of the Block Stability of Rock Slopes}

When analyzing the stability of a block based on the coordinate projection principle, it is necessary to find the elastic finite element maps of plane problems of underground engineering (Yang et al., 1989) to determine the initial stress of each interface of plane blocks in order to obtain their stability coefficient. However, the efficiency of this solution is not high for planar polyhedral blocks and blocks with curved surfaces. When solving the stability coefficients of blocks of this paper, we assume that each block exposed on the free faces is a rigid body, so the stability coefficient $\eta$ of each block can be calculated by using the following methods:

Firstly, the stability of each structural plane is analyzed, assuming that the interface stability coefficient of each structural plane is $\eta_{J}$, then it can be calculated as follow:

$$
\eta_{J}=\frac{\sigma \tan \varphi+c}{\tau}
$$

In the formula : $\sigma$ is the compressive stress of structural plane, $\mathrm{MPa} ; c$ and $\varphi$ are cohesion and friction angle of the structural plane, respectively; $\tau$ is the shear stress on structural plane, $\mathrm{MPa}$.

If $\eta_{J} \geq 1$, the structural plane is in a stable state, if $\eta_{J}<1$, the structural plane will be destroyed.
The stability analysis of a block is carried out according to the following ideas: the coefficient of a block is calculated according to the ratio of the sliding resistance on each structural plane and the sliding force of the block. If the stability coefficient of a block is set to be $\eta$, then it can be obtained by the following equation:

$$
\eta=\frac{\sum_{i=2}^{n} A_{i}\left(\sigma_{i} \tan \varphi_{i}+c_{i}\right)}{\rho g V \sin \delta}
$$

where $\rho$ is density of the rock, $\mathrm{kg} / \mathrm{m}^{3} ; \mathrm{g}$ is acceleration of gravity, $9.8 \mathrm{~m} / \mathrm{s}^{2} ; V$ is the volume of block, $\mathrm{m}^{3} ; \delta$ is the inclination angle of structural plane, $\left({ }^{\circ}\right) ; A$ is the contact area between the block and structural plane, $\mathrm{m}^{2} ; n$ is the number of structural planes acting on the block. The meanings of other symbolic are as explained before.

According to the classification standard of the degree of stability of dangerous rock masses in the "Specification for investigation of Landslide Control Engineering" (DZ/T 0218-2006), it is considered that when the stability factor of a dangerously unstable sliding rock block is $\eta<1.0$ the block is unstable, and when it is $1.0 \leq \eta<1.2$ the block may be unstable. However, when it is $1.2 \leq \eta<1.3$ the block is basically stable, and when it is $1.3 \leq \eta$ the block is stable.

\section{Geological Survey and Field Investigation of Shenxianju Rock Slope}

The Shenxianju Scenic Spot in Xianju County, Zhejiang Province, is a national $5 \mathrm{~A}$-level scenic spot with a total area of 22.32 square kilometers. The scenic spot is located in the south-central of Xianju County, Zhejiang Province, about 20 kilometers away from Xianju County (as shown in Fig. 1). Its terrain is mainly hilly and mountainous, and the landform is cliff. Also, its slope is nearly upright, the direction of slope is $278^{\circ}$, and its altitude difference is $30 \mathrm{~m}$. In the meantime, it is the largest typical volcanic rhyolite landform in the world. The scenic spot is located between the low-height hills of Eastern Zhejiang and the middle mountain of Southern Zhejiang. The elevation is $100-900 \mathrm{~m}$, and the relative altitude difference is $200-600 \mathrm{~m}$. The terrain in the scenic area is severely cut and the maximum cutting

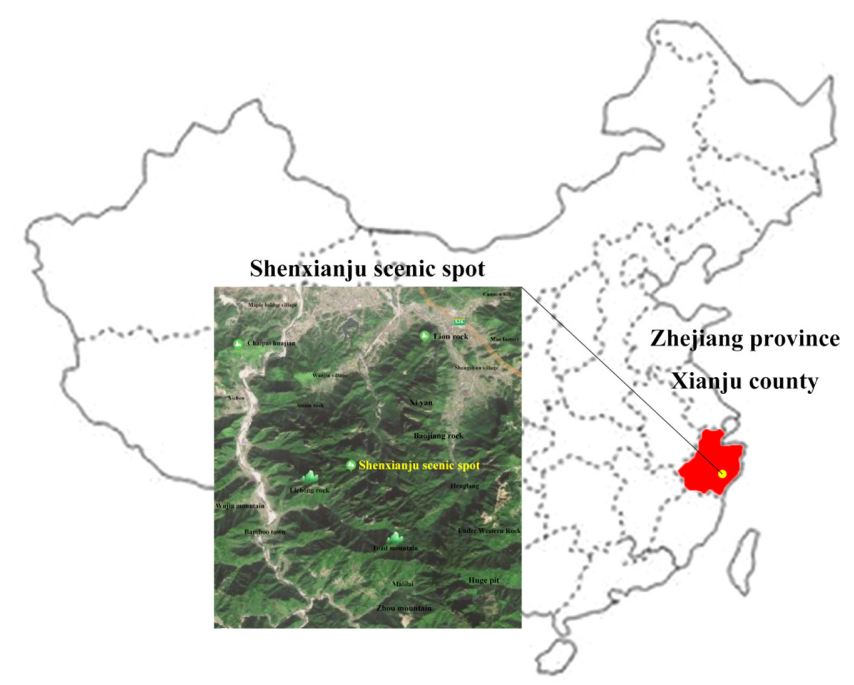

Figure 1. Geographical location map of Shenxianju Scenic Spot. 


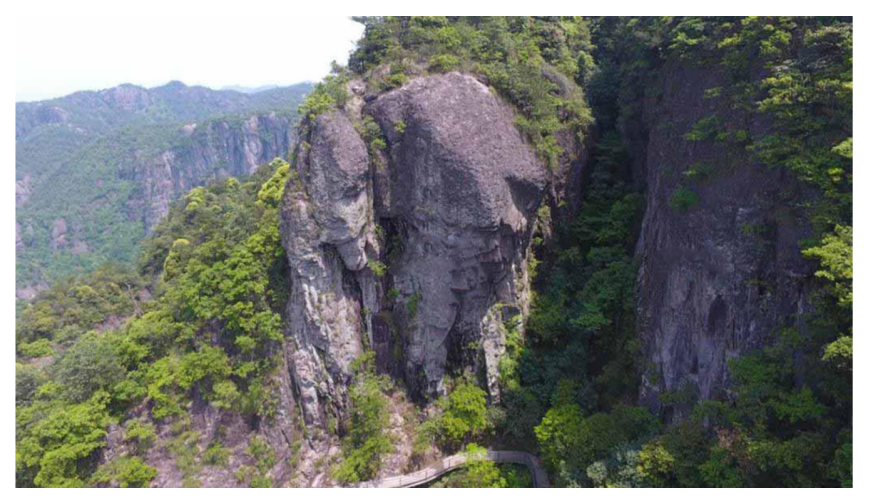

Figure 2. UAV aerial view of the rock slope in study area.

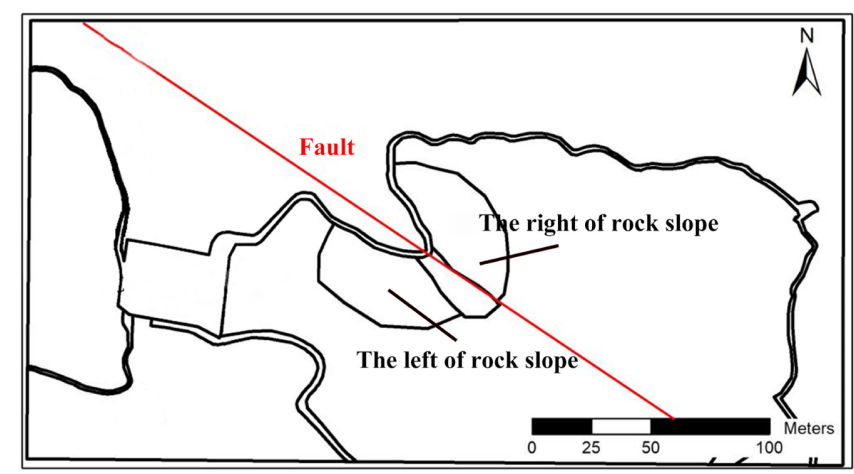

Figure 3. Faults passing through the study area.

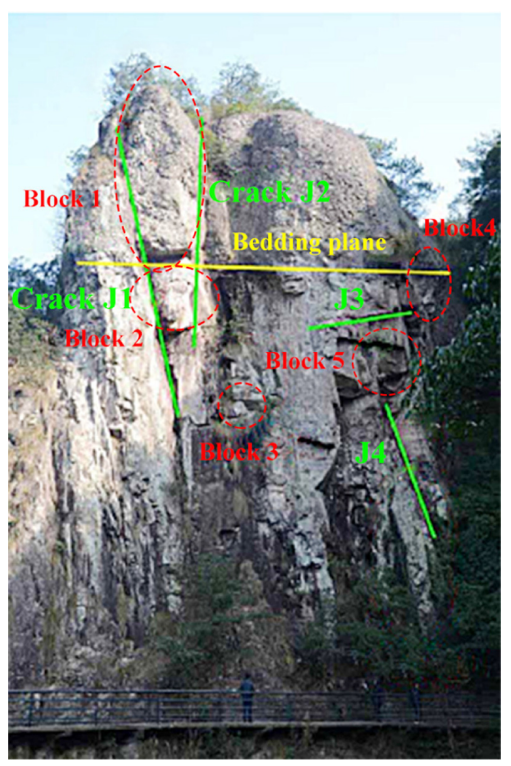

Figure 4. The distribution of rock slope cracks and joints in study area. depth is $800 \mathrm{~m}$. The changes in terrain slope are rapid, but the upper part of mountains are flat, and there are many cliffs in the middle of mountains. The terrain is steep, and the mountain body is abrupt, therefore, the instability of the block and collapse occur frequently.

In the study area, there is a fault that cuts through the rock slope, as shown in Fig. 3. The fault strike is NW with a total length of 3,700 m and medium scale of development.

The slope structure of the study area is shown in Fig. 4: the aspect of left side slope is $278^{\circ}$, the gradient of it is $85^{\circ}$, the occurrence of bedding plane is $0^{\circ} \angle 10^{\circ}$. The aspect of right side slope is $220^{\circ}$, the gradient of it is $89^{\circ}$, and the height of rock slope is $35 \mathrm{~m}$. Affected by faults, weathering erosion, rainfall, the joints and fractures of rock mass on the slope developed well. There are two groups of large fractures developed in the middle and upper part of the slope cliff in the study area, the occurrence of fracture $\mathrm{J} 1$ is $205^{\circ} \angle 85^{\circ}$, the length of it is about $15 \mathrm{~m}$, the occurrence of fracture $\mathrm{J} 2$ is $260^{\circ} \angle 90^{\circ}$, the length and spacing of it are about $15 \mathrm{~m}$ and $2 \mathrm{~m}$, respectively. The occurrences of the two groups of joints on the lower right side are $\mathrm{J} 3: 292^{\circ} \angle 30^{\circ}$ and $\mathrm{J} 4: 290^{\circ} \angle 85^{\circ}$, respectively, their spacing are $0.1-1 \mathrm{~m}$, in addition, the joint fissures cut each other.

The analysis of thin section and XRD experiment have been carried out for the samples of slope rock mass. The result shows that the rock is rhyolitic crystalline debris fused tuff, and the mainly mineral compositions of it are quartz and feldspar. Among them, quartz is about $75 \%$, orthoclase is $15 \%$, microcline is $6 \%$, pyroxene is $3 \%$, and ankerite is $1 \%$.

Fortunately, Li et al. (2017) had conducted a detailed research on slope structure, hydroclimate and laboratory tests in the study area. However, this region is affected by typhoon from July to September every year. The annual average temperature is $17.2^{\circ} \mathrm{C}$, the annual precipitation is $1,443.8 \mathrm{~mm}$, the annual evaporation is $1,189.6 \mathrm{~mm}$, the annual sunshine duration is greater than $1,785.5 \mathrm{~h}$, the annual sunshine rate reaches $40 \%$, the frost-free period is $246 \mathrm{~d}$, and the annual relative humidity is $77 \%$. The climatic conditions here are suitable for the growth of trees. Due to sufficient rainfall, weathering and erosion for the rock make the stability of the rocky decrease, they increase the possibility of geological disasters, such as collapse.

According to the "Rock test procedures for water conservancy and hydropower projects" (SL/T 264-2020), the physical and mechanical parameters of rock samples have been obtained by physical and mechanical tests as shown in Tables 1 and 2 :

According to field investigation, the slope has occurred many blocks collapse and sliding in history. Affected by faults cutting, the integrity of rock mass is poor, there are many dangerous rock masses, and there is a great risk of collapse. It is urgent to investigate the dan-

Table 1. Basic physical indexes of rocks

\begin{tabular}{ccccc}
\hline \hline Name & $\begin{array}{c}\text { Natural density } \\
\rho /\left(\mathrm{g} / \mathrm{cm}^{3}\right)\end{array}$ & $\begin{array}{c}\text { Dry density } \\
\rho_{d} /\left(\mathrm{g} / \mathrm{cm}^{3}\right)\end{array}$ & $\begin{array}{c}\text { Saturation density } \\
\rho_{w} /\left(\mathrm{g} / \mathrm{cm}^{3}\right)\end{array}$ & $\begin{array}{c}\text { Natural water content } \\
\omega / \%\end{array}$ \\
\hline Average Value & 2.57 & 2.21 & 2.31 & 4.31 \\
\hline
\end{tabular}

Table 2. Mechanical parameters of rock

\begin{tabular}{|c|c|c|c|c|c|c|}
\hline $\begin{array}{c}\begin{array}{c}\text { Moisture state } \\
\text { of specimen }\end{array} \\
\text {. }\end{array}$ & $\begin{array}{c}\text { Elastic } \\
\text { Modulus / GPa }\end{array}$ & $\begin{array}{l}\text { Poisson's } \\
\text { ratio }\end{array}$ & $\begin{array}{c}\text { Uniaxial compressive } \\
\text { strength / MPa }\end{array}$ & Cohesion / $\mathrm{MPa}$ & $\begin{array}{l}\text { Internal friction } \\
\text { angle } /\left(^{\circ}\right)\end{array}$ & $\begin{array}{c}\text { Tensile } \\
\text { strength / MPa }\end{array}$ \\
\hline Air drying & 13.36 & 0.166 & 203.46 & 20.32 & $76^{\circ}$ & 6.58 \\
\hline
\end{tabular}


gerous rock masses and calculate its stability. Therefore, taking the rock slope in Shenxianju scenic spot as the research background, the stability analysis and visualization of the block is investigated to provide reference for the prevention and control of block collapse or sliding disasters in mountainous scenic area.

\section{Methodology}

Based on coordinate projection principle, this paper uses the data obtained by UAV technology, and combines the development environment and graphics processing toolbox of Matlab software (Tang et al., 2013; Xie, 2018) to develop the CPS program. This program can determine the geometry conditions of blocks conveniently. Also, it can realize the block stability analysis and visualization so as to improve the efficiency of it.

\section{Application of UAV and Data Processing}

In this paper, the DJI Phantom 4 UAV was used to conduct the space measurement of study area. In order to ensure the flight safety and precise collection of slope information, the heading and side overlap ratio were set as $60 \%$ and $70 \%$, respectively, according to the provision of "CH/Z 3005 Low Altitude Digital Aerial Photogrammetry Specification". The relative flight altitude was $150 \mathrm{~m}$ and the image resolution was $4.1 \mathrm{~cm}$. What's more, five image control points had been distributed in aerial photography area evenly, and 122,355 aerial triangulation points had been calculated, and the mean square error of residual was $0.018 \mathrm{~m}$. The images captured by UAV aerial photography are shown in Fig. 5.

The images scanned by UAV need to be processed by Context Capture to get the required point cloud. The specific operations are : (1) Import photos and POS information files. (2) Align the position of photos and build sparse point clouds. (3) Adding control points makes the calculation of aerial triangulation more accurate. (4) Optimize camera alignment parameters to make the calculation more accurate, meanwhile, avoid some possible distortions. (5) Based on the sparse point clouds, the dense point clouds are established and outputted.

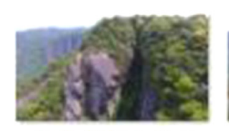

D川_0201.JPG

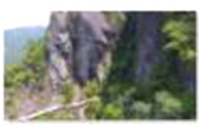

DJ_0217.JPG

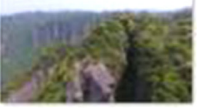

DJ_0233.JPG

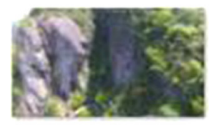

DI_0249.JPG

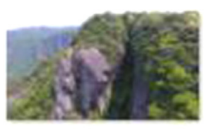

DJ_0202.JPG

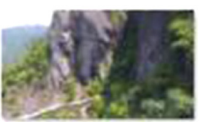

DI_0218.JPG

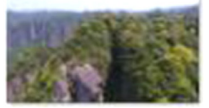

DJ_0234.JPG

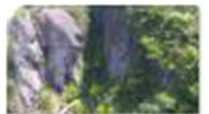

DJ_0250.JPG
DJ_0203.JPG

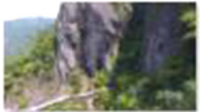

DJ_0219.JPG

DJ_0235.JPG

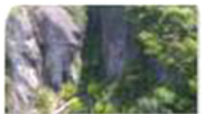

DЛ_0251.JPG
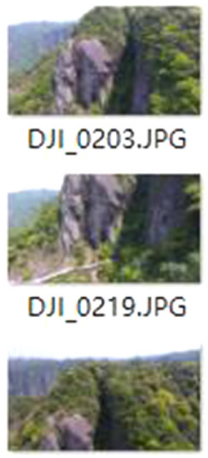

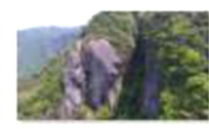

DJI0204.JPG

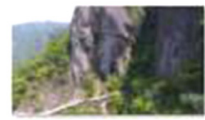

DJ_0220.JPG

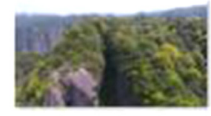

DJ_0236.JPG

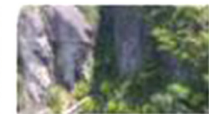

Dנ_0252.JPG
Figure 5. Aerial image of UAV (part).
The data format obtained by UAV aerial photography is polar coordinate, which needs to be converted into the rectangular coordinate that can be used by CPS program. Let one of the polar coordinates points named $\mathrm{P}$ be $(\rho, \alpha, \beta)$ and denote the rectangular coordinate of point $\mathrm{P}$ as $(x, y, z)$. The right-handed rectangular coordinate system is established with the three-dimensional laser scanner as the coordinate origin. Letter $\mathrm{O}$ is recorded as the coordinate origin and point $\mathrm{P}$ is the target point to be measured. The projection of point $\mathrm{P}$ on XOY plane is denoted as $\mathrm{P}^{\prime}$, and the projection of point $\mathrm{P}$ on plane $\mathrm{ZOY}$ is denoted as $\mathrm{P}$ ", then the rectangular coordinate of point $\mathrm{P}$ can be expressed as:

$$
\left\{\begin{array}{c}
x=\rho \sin \beta \\
y=\rho \sqrt{\cos ^{2} \beta-\sin ^{2} \alpha} \\
z=\rho \sin \alpha
\end{array}\right.
$$

\section{Block Stability Analysis Program - CPS}

\section{CPS-I program}

The main function of CPS-I program is to build a three-dimensional visualization model of rock slope. The images obtained by UAV need to be processed using Context Capture to get the required point cloud data, then the polar point cloud data processed by the software is converted to rectangular coordinate by Eq. (12). After that, the point cloud data available for CPS program is obtained (as shown in Fig. 6). Afterward, import the point cloud data into the CPS-I program, and the three-dimensional model of rocky slope is constructed by calling the Matlab drawing toolbox. The three-dimensional reality image of the slope built by point cloud is obtained, that is, the threedimensional visualization model of the rock slope. The converted point cloud data is represented by a matrix of $\mathrm{n}$ rows $* 6$ columns : each row represents a data point, where the first three columns record the $x, y, z$ coordinates of the points, and the last three columns are the color matrix which indicate the colors of the points.

\section{CPS-II program}

CPS-II program mainly realizes the automatic identification and fitting of structural planes, which is divided into two subroutines: CPS-II-1 and CPS-II-2. Among them, the CPS-II-1 program uses an improved region growing algorithm to search a structural plane from the three-dimensional visualization model automatically (as shown in Fig. 7), meanwhile, it can construct a structural plane equation and visualize it. CPS-II-2 program adopts a method of human-computer

\begin{tabular}{|c|c|c|c|c|c|c|c|}
\hline & 1 & 2 & 3 & 4 & 5 & 6 & 7 \\
\hline 26 & 7.4890 & 0.8970 & -0.2030 & 102 & 104 & 125 & \\
\hline 27 & 4.6220 & 9.5380 & -5.1640 & 136 & 127 & 140 & \\
\hline 28 & 7.4940 & 0.8990 & -0.3130 & 112 & 115 & 136 & \\
\hline 29 & 7.4840 & 0.7590 & -0.2190 & 112 & 115 & 139 & \\
\hline 30 & 8.3660 & 4.9080 & 1.8180 & 116 & 98 & 106 & \\
\hline 31 & 7.4890 & 0.9540 & -0.2580 & 125 & 126 & 146 & \\
\hline 32 & 4.6580 & 9.4270 & -5.1750 & 192 & 182 & 199 & \\
\hline 33 & 7.4830 & 0.8740 & -0.3310 & 99 & 102 & 124 & \\
\hline 34 & 8.4200 & 4.7900 & 1.8230 & 141 & 122 & 132 & \\
\hline 35 & 7.4990 & 0.8420 & -0.2580 & 141 & 143 & 166 & \\
\hline 36 & 7.4940 & 0.7860 & -0.2020 & 118 & 120 & 144 & \\
\hline
\end{tabular}

Figure 6. Point cloud data of slope. 


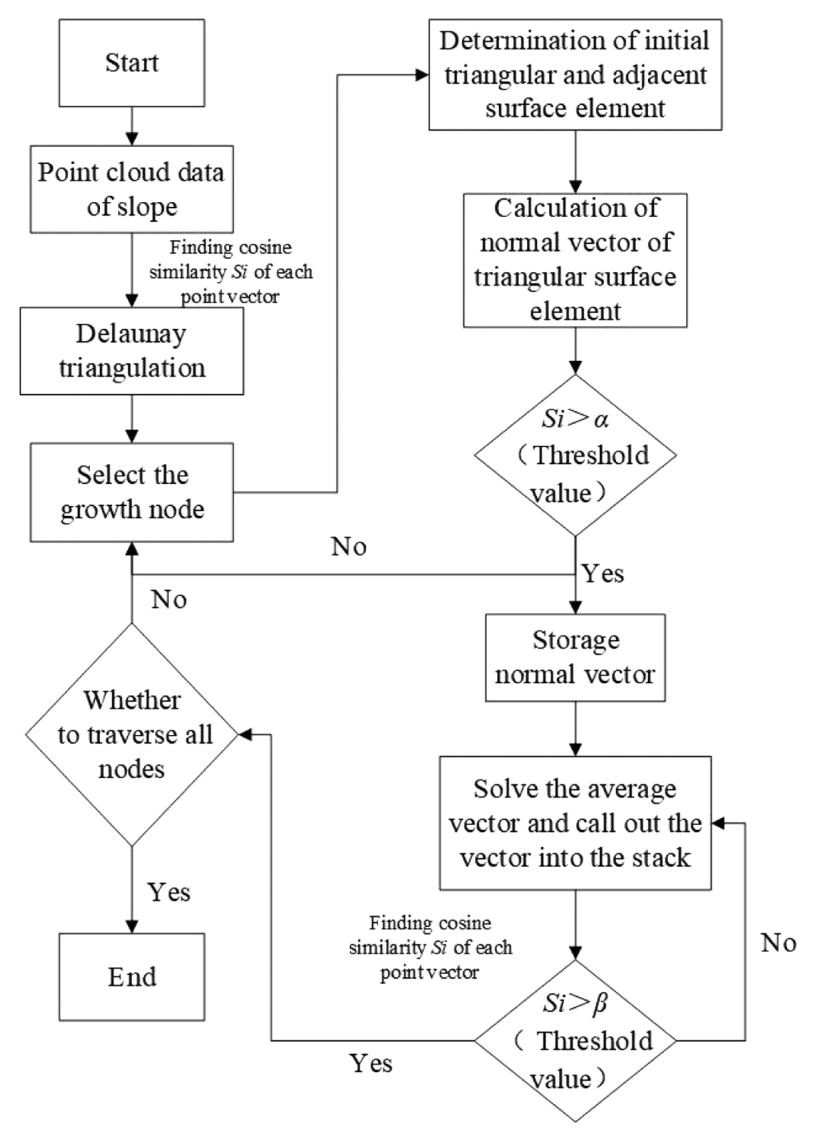

Figure 7. Flow chart of automatic discontinuity recognition.

\begin{tabular}{|c|c|c|}
\hline 字段 & (19) Target & Position \\
\hline 1 & $1 \times 1$ Scatter & {$[1.9100,14.0190,-13.0630]$} \\
\hline 2 & 1x1 Scatter & {$[7.0350,6.8540,-3.1350]$} \\
\hline 3 & $1 \times 1$ Scatter & {$[8.4070,-4.4170,-1.9180]$} \\
\hline 4 & $1 \times 1$ Scatter & {$[3.8840,10.4890,2.3880]$} \\
\hline 5 & 1x1 Scatter & {$[4.4520,13.6180,-6.4430]$} \\
\hline 6 & 1x1 Scatter & {$[1.5060,10.5090,-21.1800]$} \\
\hline 7 & 1x1 Scatter & {$[1.4720,-3.4620,-27.1970]$} \\
\hline 8 & $1 \times 1$ Scatter & {$[1.4550,12.4760,-18.7030]$} \\
\hline 9 & 1x1 Scatter & {$[1.0980,6.3720,-22.8890]$} \\
\hline 10 & $1 \times 1$ Scatter & {$[1.1760,2.3560,-26.2170]$} \\
\hline
\end{tabular}

Figure 8. Control points of the curved surface.

interaction. According to the three-dimensional visualization model of rock slope, the points on the structural plane are manually selected. This part can supplement the structural planes which cannot be identified automatically and establish their equations so as to realize visualization of them. The calculation results are spatial representation of the structural planes.

\section{CPS-III program}

The main function of CPS-III program is to construct a free face

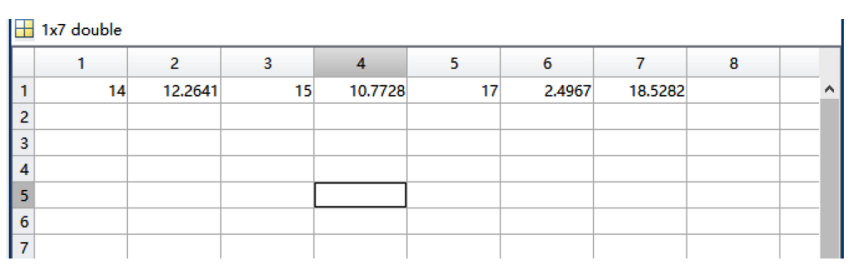

Figure 9. Output results of block geometry information.

equation and identify the finite closed blocks. The input data is the preprocessed data obtained by UAV and the structural plane data identified by CPS-II. The output data is the control point data of free face equations and the state data of blocks, we select the structural plane manually and ignore the influence of other structure planes on the selected one. For the block composed of free faces and structural planes after the manual selection, a limited judgment is required $: n$ horizontal planes of different heights are used to cut a curved surface block, then, the curved surface is divided into multiple straight lines, and you can get $\mathrm{n}$ section graphs. If the straight lines in each section graph can form a closed figure, it can be considered that this block is closed, and then the closed blocks in the rock slope are determined.

\section{CPS-IV program}

The main function of CPS-IV is geometric analysis. Primarily, the possibility of instability of a closed block is judged, and then the possible unstable block is determined and the volume and boundary surface area of it are calculated. The closed block data obtained by CPSIII program is used to judge the tendency of sliding surface of it. It is generally considered that the anti-dip blocks are stable, so only the down-dip blocks need to be analysed. The output results are the volume of the possibly unstable blocks and the area of the structural planes. The first column represents the serial number of the first selected structural plane, and the second column represents the area of it. The third column indicates the serial number of the second selected structural plane, and the fourth column indicates the area of it. The fifth column indicates the serial number of the third structural plane, the sixth column indicates the area of it, and the last column indicates the volume of the block cut by the above structural planes.

\section{CPS-Vprogram}

The main function of CPS-V program is block stability analysis and visualization. According to the geometric parameters of closed blocks obtained by CPS-IV program, the stability coefficient of each block is calculated by Eq. (11) in the program. The output results are divided into two parts : data display and graphic display. In the data display results, the CPS-V shows the numbers of the possible unstable and unstable blocks, the numbers of the structural planes constituting the blocks, and their stability coefficients. In the graphic display results, the CPS-V program calls MATLAB graphic processing toolbox to show the various structural planes that constitute the blocks in different colors, meanwhile, the positions of the possible unstable and unstable blocks are revealed in the rock slope model.

It can be seen that the CPS program developed based on coordinate projection method can integrate the information of structural planes 


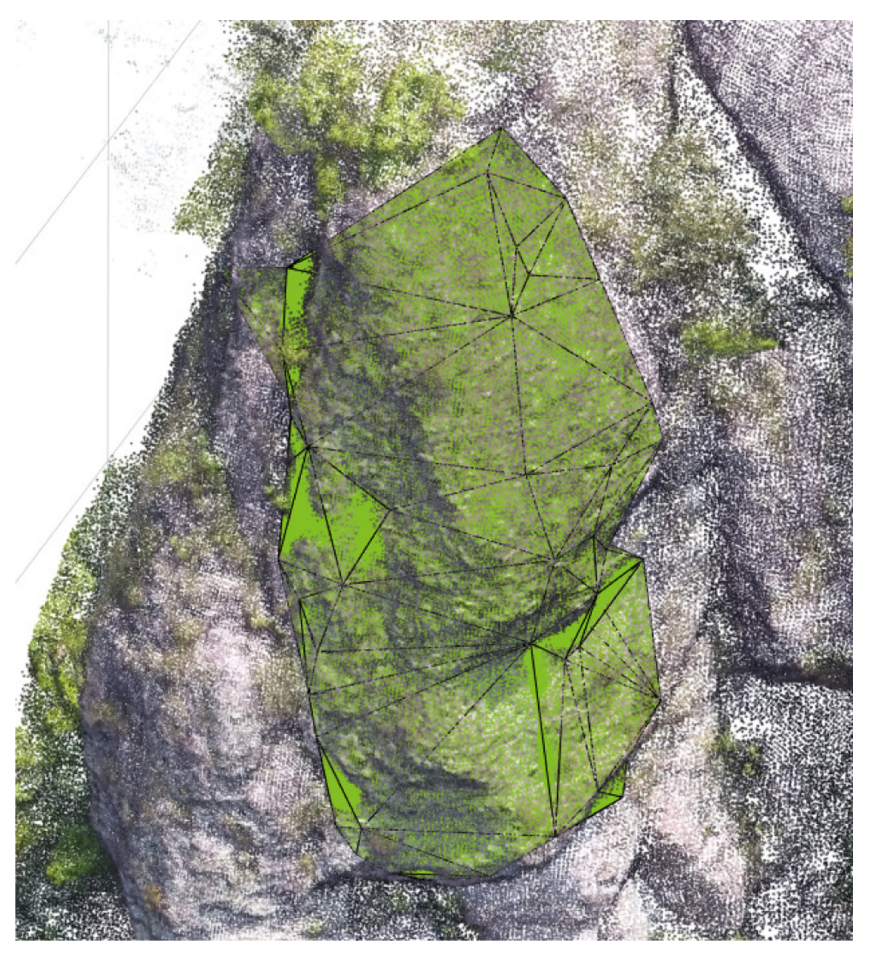

Figure 10. Visualization of the block.

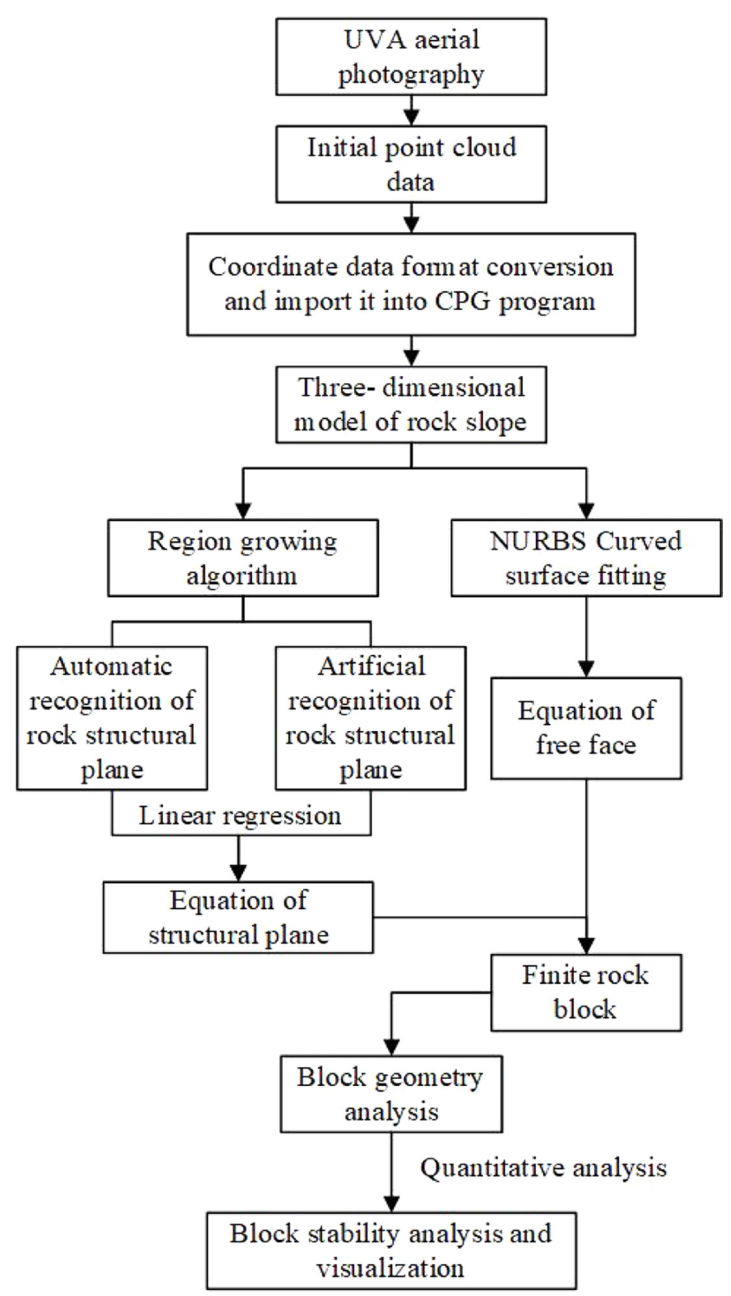

Figure 11. The flow chart of Methodology. and free faces comprehensively. There are many superiorities of this program, such as expressing the geometric conditions of blocks conveniently, solving the problems of describing the geometric conditions of blocks with complex shapes and multiple blocks, and improving the analysis efficiency.

\section{Program Application and Result Analysis}

In order to verify the reliability of program and analysis results, the CPS program is used to analyze the stability of the rock slope in the study area of Shenxianju. The specific process is as follows:

(1) The preprocessing point cloud data (as shown in Fig. 6) was imported into the CPS-I program which was run to establish the visualization of rock slope and the three-dimensional model (as shown in Fig. 12).

(2) According to the model obtained from previous step, run the CPS-II program, the structural planes were selected by two subroutines automatically and manually, after that, 19 structural planes and their equation coefficients could be obtained as shown in Fig. 13.

(3) Combined with the output data of CPS-II program, run CPS-III program to get the information about possible unstable blocks (as

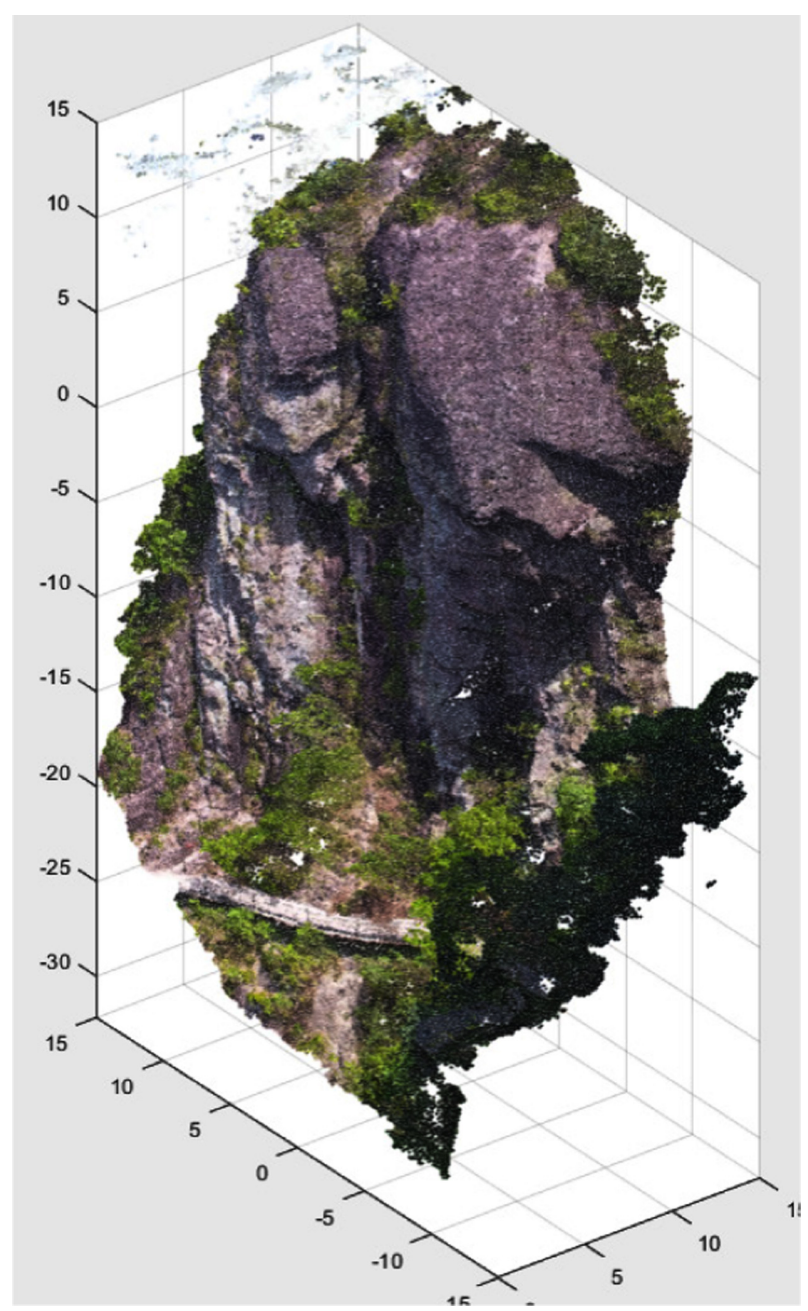

Figure 12. 3D model visualization of rock slope. 


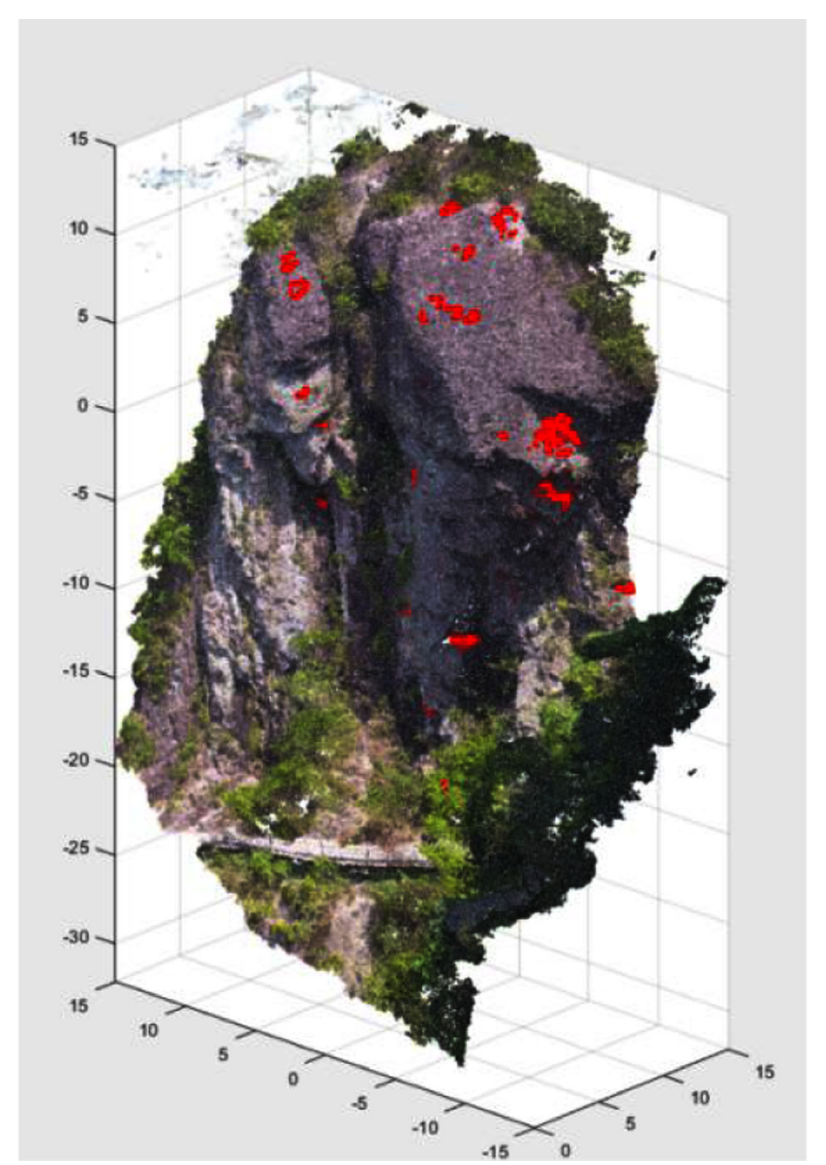

Figure 13. The structural planes of rock slope.

\begin{tabular}{|r|r|r|r|r|}
\hline & 1 & 2 & 3 & 4 \\
\hline 1 & 1 & 3 & 5 & 8 \\
\hline 2 & 1 & 10 & 13 & 14 \\
\hline 3 & 1 & 14 & 15 & 17 \\
\hline 4 & 1 & 14 & 16 & 19 \\
\hline 5 & 1 & 11 & 18 & 19 \\
\hline 6 & 0 & 1 & 3 & 7 \\
\hline 7 & 0 & 13 & 14 & 15 \\
\hline 8 & 0 & 6 & 8 & 13 \\
\hline 9 & 0 & 7 & 14 & 16 \\
\hline
\end{tabular}

Figure 14. Output results of CPS-III program.

shown in Fig. 14). The first column denoted the closure states of the blocks, among them, ' 1 ' denoted closure, ' 0 ' denoted non-closure, and the last three columns were the number of structural planes. Then the
CPS-IV program was used to determine the equations of free face (such as the control points of the curved surface shown in Fig. 8) so as to identify the finite blocks and calculate the volume of the closed blocks and the area of each interface of them (as shown in Table 3).

Sun et al. (2017) had made detailed statistics on the occurrence of slope joints. In order to count the occurrences of joints so as to identify the dangerous rock areas in the rock slope, we selected 79 occurrence data of structural planes (237 3D point data) on the real model of high and steep slope to calculate the occurrence characteristics of rock mass structure. The joint contour map was drawn by the calculation results and DIPS tool (as shown in Fig. 15). The analysis results showed that the joint fissure tendencies on the high and steep slope in the study area were mainly southward and northeastward, and the dip angles were $70^{\circ}-89^{\circ}$. The existences of multiple sets of joints cut the rock mass into several dangerous rock blocks. Under the action of weathering, the strength of structural planes of the rock mass decreased continuously resulting in collapse of dangerous rock blocks under gravity.

In order to verify the reliability of the results calculated by CPS program, according to the coefficients of structural planes, the occurrence information of No.14,16,19 structural planes were calculated by Eqs. (1) and (2). The results were $240^{\circ} \angle 80^{\circ}, 110^{\circ} \angle 30^{\circ}, 56^{\circ} \angle 25^{\circ}$. The results were basically consistent with the actual situation. Therefore, it could be judged that the method of using this program to obtain the structural plane occurrences quickly was feasible and the model generated was reliable.

(4) Parameters such as weight density $\gamma$, poisson ratio $\mu$, cohesion $C$ and internal friction angle $\varphi$ of blocks were input in CPS-V program, and a stability coefficient of the block was calculated (as shown in Table 3). At the same time, the positions of closed blocks in the rock slope were displayed in the program (as shown in Fig. 17), which realized the visualization of the possible unstable blocks.

Through graphic display, the positions of these blocks in rock slope were obtained, and the visualization of the possibly unstable blocks was realized, as shown in Fig. 16. From the calculation results of the program, it could be seen that the stability coefficient of No. 4 block was 0.9188 , which was less than 1 , so it could be considered as an unstable block. The stability coefficient of No. 3 block was 1.1939 , so it could be considered as a potentially unstable block which had a possibility of instability. Engineering practice showed that No. 4 block slipped in April 2017 without causing casualties. The rockfalls hit the garbage bin on one side of the road in the study area, and the stone size was about $0.4 \mathrm{~m} \times 0.8 \mathrm{~m} \times 0.1 \mathrm{~m}$. No. 3 block has not yet slipped, but it needs to be reinforced and supported.

In order to verify the reliability of CPS program analysis results, the $Q$-slope method (Bar and Barton, 2017) was used for a comparative

Table 3. Table of blocks stability coefficient

\begin{tabular}{cccccc}
\hline \hline $\begin{array}{c}\text { The Number } \\
\text { of Block }\end{array}$ & $\begin{array}{c}\text { The number of } \\
\text { structural plane }\end{array}$ & $\begin{array}{c}\text { The Area of Structural } \\
\text { plane } / \mathrm{m}^{2}\end{array}$ & $\begin{array}{c}\text { The Volume of } \\
\text { Block } / \mathrm{m}^{3}\end{array}$ & $\begin{array}{c}\text { Stability } \\
\text { coefficient }\end{array}$ & Stable state \\
\hline 1 & $3,5,8$ & $6.8646,5.4562,8.4354$ & 4.7223 & 1.3658 & Stable \\
2 & $10,13,14$ & $3.6451,9.1856,5.8432$ & 4.6785 & 1.2974 & Basically unstable \\
3 & $14,15,17$ & $8.2614,10.7728,3.8527$ & 3.5282 & 1.1939 & Potentially unstable \\
4 & $14,16,19$ & $2.5821,12.7269,4.2834$ & 7.6591 & 0.9118 & Unstable \\
5 & $11,18,19$ & $6.4684,7.4653,4.9530$ & 3.7868 & 1.8533 & Stable \\
\hline
\end{tabular}




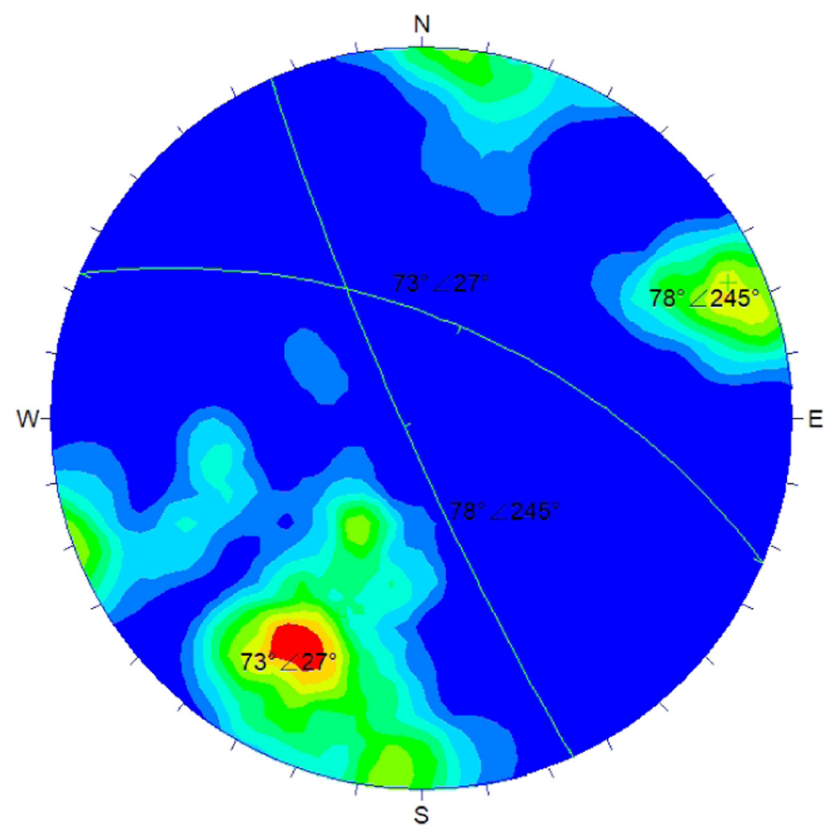



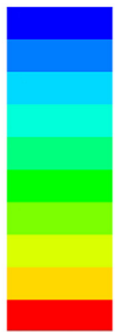

$0.00 \sim 1.00 \%$

$1.00 \sim 2.00 \%$

$2.00 \sim 3.00 \%$

$3.00 \sim 4.00 \%$

$4.00 \sim 5.00 \%$

$5.00 \sim 6.00 \%$

$6.00 \sim 7.00 \%$

$7.00 \sim 8.00 \%$

$8.00 \sim 9.00 \%$

$9.00 \sim 10.00 \%$

No Bias Correction

Max. Conc. $=9.9018 \%$

Equal Angle

Lower Hemisphere

79 Poles

79 Entries

Figure 15. Joint contour map.
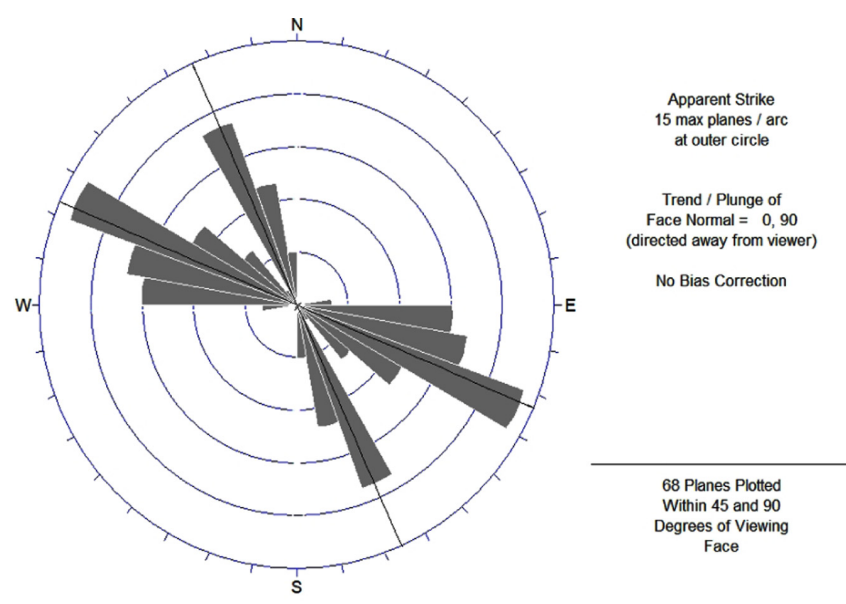

Figure 16. Rose diagram and scatter diagram of joints.

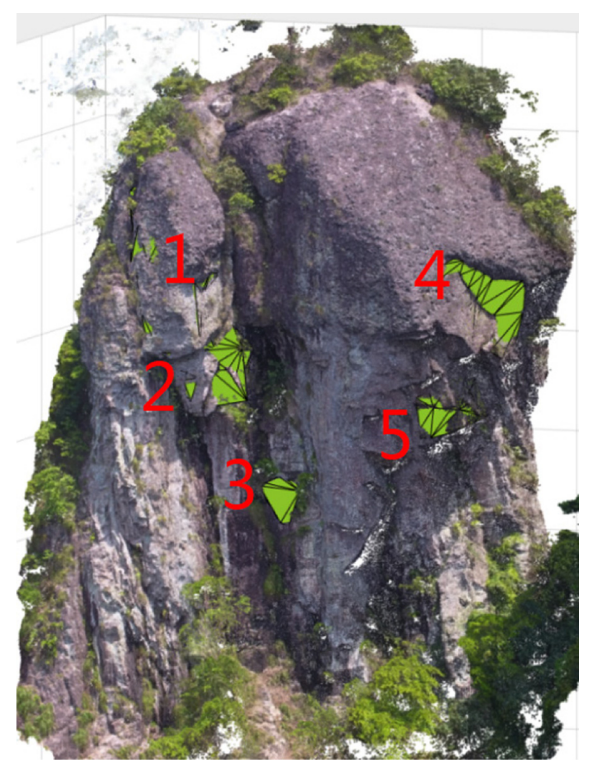

Figure 17. The diagram of possible unstable blocks.

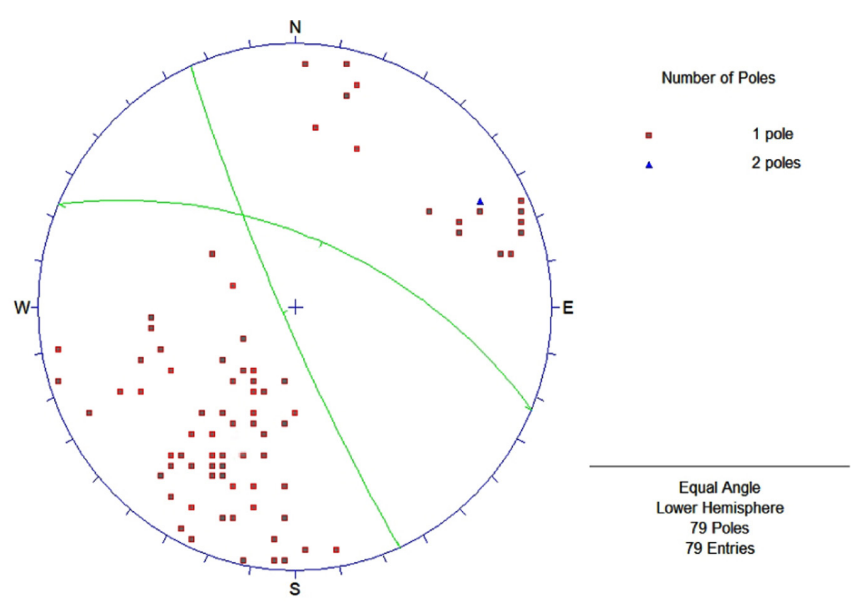

analysis of rock slope in study area. According to the geological conditions of rock slope in the field investigation, it could be obtained : Rock quality designation $(R Q D)=95$, Number of joint sets $J_{\mathrm{n}}=15$, Roughness of joints $J_{\mathrm{r}}=3.0$, Joint alteration degree $J_{\mathrm{a}}=2.0$, Water reduction coefficient of joints $J_{\mathrm{w}}=0.9$, Stress reduction coefficient $S R F=3$, the calculation formula of $Q$ was as follows:

$$
Q=\frac{R Q D}{J_{n}} \times \frac{J_{r}}{J_{a}} \times \frac{J_{w}}{S F R}
$$

The combination of the six parameters reflects three aspects of rock mass quality, that is, $\frac{R Q D}{J_{n}}$ is the integrity of rock mass, $\frac{J_{r}}{J_{a}}$ represents the morphology of structural planes (joints), the characteristics of filler and the degree of secondary change. $\frac{\vec{J}_{w}}{S F R}$ represents the influence of water and other stresses on rock mass quality. After calculation, $Q=2.85$, and the following conclusion based on the height of rock slope $(H=30 \mathrm{~m})$ and the size of the $Q$ value could be obtained : the grade classification of the rock slope was poor and it needed to be supported. This was basically consistent with the program settlement results. 


\section{Summary}

Based on a rock slope in Shenxianju, Xianju County, Zhejiang Province, this paper proposes a stability analysis method combining UAV measurement technology and coordinate projection. According to the point cloud data obtained by UAV aerial photography, the equations of structural planes and free faces are fitted. The geometric analysis of blocks cut from the structural planes and free faces is carried out. After that, the stability coefficients of blocks are calculated. Finally, the unstable blocks are determined. Based on MATLAB, the CPS program suitable for the stability analysis of planar polyhedron blocks and curved surface blocks in rock slope engineering is developed. This program can realize the spatial representation of structural planes, free faces and unstable blocks of rock slope, meanwhile, visualize them.

\section{Conclusion}

(1) There are many superiorities to use UAV aerial photography technology, such as large amounts of information, high precision, celerity and no influence on the measured objects. Most important of all, the point cloud data obtained from UAV aerial images can well construct the three-dimensional model of rock slope.

(2) The coordinate projection principle can deal with the geometric information on the block conveniently, and calculate the interface area and volume of the blocks cut by structural planes and free faces. Combined with topological search and vector analysis, the quantitative analysis is carried out to determine the specific location of finite closed blocks of the slope and possible unstable blocks. Through the stability calculation and analysis of possible unstable blocks, the unstable blocks of the rock slope are determined finally.

(3) The CPS program developed based on MATLAB reconstructs the surface of point cloud by importing point cloud data, and fits the structural planes and free faces so as to construct the 3D model of rock slope. Automatic structural planes searches are realized to identify possible unstable blocks, finally, the stability analysis and visualization of blocks come true.

(4) Through the analysis and comparison to an engineering example : the analysis results of CPS program are basically consistent with that of $Q$-slope, that is to say, the stability analysis results of rock slope block are reliable.

\section{Acknowledgement}

The research received funding from the National Key Research and Development Program of China (2019YFC1509703).

\section{References}

Azarafza, M., Akgün, H., Feizi-Derakhshi, M.R., Azarafza, Me., Rahnamarad, J., and Derakhshani, R., 2020, Discontinuous rock slope stability analysis under blocky structural sliding by fuzzy key-block analysis method. Heliyon, v. 6, e03907. doi:10.1016/j.heliyon.2020.e03907

Azarafza, M., Akgün, H., Ghazifard, A., and Asghari-Kaljahi, E., 2020,
Key-block based analytical stability method for discontinuous rock slope subjected to toppling failure. Computers and Geotechnics, v. 124, 103620. doi:10.1016/j.compgeo.2020.103620

Bar, N., and Barton, N., 2017, The Q-Slope Method for Rock Slope Engineering. Rock Mechanics and Rock Engineering, v. 50, pp. 3307-3322. doi:10.1007/s00603-017-1305-0

Cai, M.F., He, M.C., and Liu, D.Y., 2002, Rock Mechanics and Engineering. Science Press, Beijing, $379 \mathrm{p}$.

Fan, Y.Y., 2004, Study and development on free-form surface reconstruction technology based on NURBS. Tianjin University, Tianjin, Master thesis, kns.cnki.net/kcms/detail/detail.aspx?FileName=2004075528.nh\&DbName $=$ CMFD2004.

Gao, B.L., 2005, Coordinate Projection method's computerization and its application to stability analysis of the structural plane and block. Xi'an University of Science and Technology, Xi'an, Master thesis, kns.cnki.net/ $\mathrm{KCMS} /$ detail/detail.aspx?dbname $=$ CMFD 0506\&filename $=2005079704 . \mathrm{nh}$.

Gao, B.L., Li, L., Chen, L.C., and Yang, Z.F., 2021, Visual research and determination of structural plane and free face of rock slopes. Environmental Earth Sciences, v. 80. doi:10.1007/s12665-020-09340-5

Goodman, R.E., and Shi, G.H., 1985, Block theory and its application to rock engineering. Prentice Hall, NJ, U.S.A., pp. 103-105.

Gu, D.Z., 1983, Foundation of Rock Mass Engineering Geomechanics. Science Press, Beijing, $24 \mathrm{p}$.

Ikegawa, Y., and Hudson, J.A., 1992, A novel automatic identification system for three- dimensional multi-block systems. Engineering Computations, v. 9, pp. 169-179.

Jiang, Q.H., and Zhou, C.B., 2017, A rigorous solution for the stability of polyhedral rock blocks. Computers and Geotechnics, v. 90, pp. 190-201. doi:10.1016/j.compgeo.2017.06.012

Kesong, N., Ning, Y.J., Yang, J., Shao, Y.B., and Wang, Z.X., 2020, A robust contact detection algorithm based on the Contact Theory in the three-dimensional discontinuous deformation analysis. International Journal of Rock Mechanics and Mining Sciences, v. 134, 104478. doi:10.1016/j.ijrmms.2020.104478

Li, C., Li, L.H., Wang, X.L., and Liao X.H., 2017, The stability evaluation of rock mass bassed on FLAC 3D and 3DEC numerical simulation technology. Journal of Engineering Geology, v. 25, pp. 48-54. doi:10.13544/j.cnki.jeg.2017.s1.094

Liu, C., Liu, X.L., Peng, X.C., Wang, E.Z., and Wang, S.J., 2019, Application of 3D-DDA integrated with unmanned aerial vehicle-laser scanner (UAV-LS) photogrammetry for stability analysis of a blocky rock mass slope. Landslides, v. 16, pp. 1645-1661. doi:10.1007/s10346-01901196-6

Lin, D., Fairhurst, C., and Starfield, A.M., 1987, Geometrical identification of three- dimensional rock block systems using topological techniques. International Journal of Rock Mechanics and Mining Sciences \& Geomechanics Abstracts, v. 24, pp. 331-338. doi:10.1016/01489062(87)92254-6

Ma, K., Liu, G.Y., Guo, L.J., Zhuang, D.Y., and Collins, D.S., 2020, Deformation and stability of a discontinuity-controlled rock slope at Dagangshan hydropower station using three-dimensional discontinuous deformation analysis. International Journal of Rock Mechanics and Mining Sciences, v. 130, 104313. doi:10.1016/j.ijrmms.2020. 104313

Shi, G.H., 1977, Stereoscopic projection method for rock stability analysis. Science in China, v. 20, pp. 260-271. doi:CNKI:SUN:JAXK.0.197703-006

Sun, J.J., Wang, X.L., Chen, Z.G., Li, L.H., Tu, X.B., Wang, Y.B., and Liao, X.H., Characteristics of rock mass structure and prediction of rock mass behavior of high-steep slope. Journal of Engineering Geology, v. 25, pp. 407-414. doi:10.13544/j. cnki.jeg.2017.s1.063.

Sun, Y.K., and Gu, X., 1984, Application of Chiping's polar projection in rock mass engineering geomechanics. Science Press, Beijing, 148 p.

Song, B., Zheng, N.S., Li, D.W., Li, D.W., Chen R.L., and Li, L., 2015, Reconstructing DEM using TLS point cloud data and NURBS surface. Transactions of Nonferrous Metals Society of China, v. 25, pp. 3165- 
3172. doi:10.1016/S1003-6326(15)63947-4

Tang, G.P., Zhao, L.H., Li, L., Gao, L.S., and Tan, H.H., 2013, Development of limit upper limit analysis program for slope stability based on Matlab. Rock and Soil Mechanics, v. 34, pp. 2091-2098. doi:10.16285/ j.rsm.2013.07.013

Wang, S.J., Yang, Z.F., and Liu, Z.H., 1984, Stability analysis of underground engineering rock mass. Science Press, Beijing, $254 \mathrm{p}$.

Xie, L.H., 2018, Slope Stability Analysis Based on MATLAB Optimization Toolbox. Shanxi Architecture, v. 44, pp. 86-87. doi:10.13719/j.cnki.cn141279/tu.2018.14.044

Yang, Y., Pan, M., Wu, G.Y., Liu, Y., and Li, K.X., 2015, Sealed Geological Block Modeling in 3D Geological Structural Model. Journal of Computer-Aided Design \& Computer Graphics, v. 27, pp. 1929-1935. doi:CNKI:SUN:JSJF.0.2015-10-015

Yang, Z.F., 1978, Stability Analysis and Evaluation of Rock Slope Blocks. In: Geotechnical Engineering Problems of Rock Masses (II). Science Press, Beijing, pp. 136-155.

Yang, Z.F., 1985, Block coordinate projection mapping method and determination of block geometry. In: Geotechnical Engineering Problems of Rock Masses (III). Science Press, Beijing, pp. 171-202.

Yang, Z.F., Ding, E.B., and Zhang, S.Q., 1989, Elastic finite element pattern SPM in the plane strain problems for underground engineering. Science Press, Beijing.

Yang, Z.F., Gao, B.L., Zhang, L.Q., and Zeng, Q.L., 2006, Computer descrip-

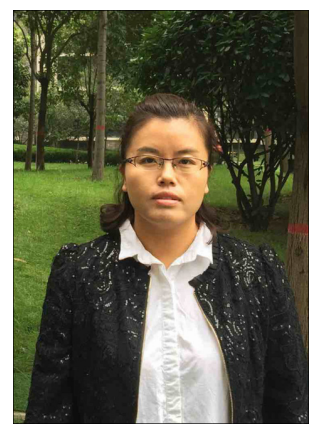

Bingli Gao, She is a National Registered Civil (Geotechnical) Engineer, and she is a director of the 8th Shaanxi Society of Geotechnical Mechanics and Engineering. She is mainly engaged in geotechnical engineering, slope engineering, ancient engineering, disaster prevention and mitigation engineering etc. More than 20 papers have been published by her as the first author, and 1 monograph, 2 teaching materials, 2 local standards of Shaanxi province engineering construction, 1 patent of invention, 3 practical new patents and 2 software copyright have been done; she is in charge of projects on underground engineering, slope engineering and ancient engineering for long term.

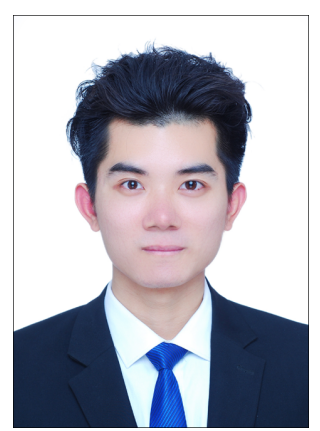

Duo $\mathbf{L i}$, he is a postgraduate student of Xi'an University of Science and Technology, mainly studying disaster prevention and mitigation engineering, ancient engineering and geotechnical engineering. tion and application of structural planes and blocks based on coordinate projection diagram. Chinese Journal of Rock Mechanics and Engineering, v. 25, pp. 2392-2398. doi:CN KI:SUN:YSLX.0.2006-12-004

Yang, Z.F., Wang, S.J., and Gao, B.L., 2009, Coordinate projection mapping method and its application in rock block stability analysis. Science Press, Beijing, 165 p.

Yu, Q.C., Xue, G.F., and Chen, D.J., 2007, General block theory of rock mass. China Water Resources and Hydropower Press, Beijing.

Yuan, G.X., Zeng, Q.L., Yang, Z.F., Shang, Y.J., and Shi, Y.Y., 2007, Coordinate projecting method and its application in the stability analysis of rock slope. The Chinese Journal of Geological Hazard and Control, v. 18, pp. 102-107. doi:CNKI:SUN:ZGDH.0.2007-03-023

Yuan, G.X., Zhang, L.Q., and Yang, Z.F., 2009, Graphic method of geometrical conditions of curved structural planes and its application. Geotechnical Engineering Technology, v. 23, pp. 5-8. doi:CNKI:SUN: YTGJ.0.2009-01-005

Zhang, L.L., Sherizadeh, T., Zhang, Y.W., Sunkpal, M., Liu, H.J., and Yu, Q.C., 2020, Stability analysis of three-dimensional rock blocks based on general block method. Computers and Geotechnics, v. 124, 103621. doi:10.1016/j.compgeo.2020.103621

Zhang, Q.H., Ding, X.L., and Wu, A.Q., 2017, A comparison of the application of block theory and 3D block-cutting analysis. International Journal of Rock Mechanics and Mining Sciences, v. 99, pp. 39-49. doi:10.1016/j.ijrmms.2017.09.005

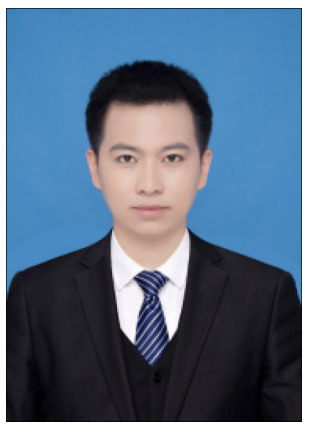

Lang $\boldsymbol{L i}$, he is an assistant engineer, mainly engaged in geological disaster exploration, design and supervision.

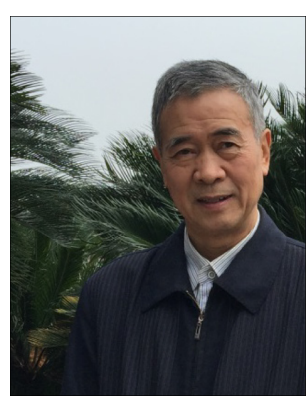

Zhifa Yang, he is a research fellow at the Institute of Geology and Geophysics, Chinese Academy of Sciences. He was secretariat general and managing director of the 4th and 5 th Chinese Society of Rock Mechanics and Engineering. He is engaged in the study of theory, methods, techniques and applications of the intersection of two disciplines between engineering geology and rock mechanics for long term, the new research direction of engineering geomechanics information research on ancient engineering was opened for the first time and important research results were achieved by him. 